\title{
Evaluasi Tingkat Kerusakan Dan Estimasi Biaya Perbaikan Bangunan Guna Sustainability Gedung Di Universitas Jember (Studi Kasus : Gedung 1 Fakultas Keguruan dan Ilmu Pendidikan (FKIP))
}

\author{
(Assement Of The Building Damage And Cost Estimation of Repairing Buildings \\ For The Sustainable Of Buildings In Jember Univeristy \\ (Case Study : Faculty of Teacher Education and Training Building 1)) \\ Wisnu Eka Nanda, Anik Ratnaningsih"), Dwi Nurtanto \\ Program Studi Teknik Sipil, Fakultas Teknik, Universitas Jember \\ Jl. Kalimantan 37 Jember 68121 \\ ${ }^{*}$ Penulis Korespondensi E-mail: anik.teknik@unej.ac.id
}

\begin{abstract}
Abstrak
Sustainability bangunan gedung sangat dipengaruhi oleh periode penggunaan atau keberfungsian dari bangunan. Agar supaya periode penggunaan sesuai dengan perencanaan, maka pemeliharaan bangunan perlu dilakukan secara berkala terhadap kerusakan dari komponen-komponen bangunan gedung sehingga dapat menjaga tingkat kenyamanan dari para pengguna bangunan gedung tersebut. Tujuan dari penelitian ini adalah untuk mendapatkan indeks kondisi bangunan berdasarkan tingkat kerusakannya, skala prioritas perbaikan, serta estimasi angaran biaya perbaikan bangunan. Evaluasi dilakukan pada Gedung 1 FKIP Universitas Jember. Metode untuk mendapatkan Indeks Kondisi Bangunan dilakukan melalui survey lapangan dengan cara pembobotan komponen dan sub-komponen bangunan menggunakan Analytical Hierarchy Process (AHP). Hasil analisis didapatkan Indeks Kondisi Bangunan Gedung 1 FKIP Universitas Jember sebesar $87,85 \%$ yang berarti gedung masih berada dalam kondisi sangat baik, dan tingkat kerusakan sebesar $12,15 \%$ yang membutuhkan perbaikan. Estimasi biaya perbaikan didapatkan berdasarkan volume kerusakan masing-masing komponen bangunan gedung dengan nilai sebesar Rp. 48.652.000,00 dengan skala prioritas perbaikan tertinggi pada komponen dinding sebesar $25,9 \%$.
\end{abstract}

Kata Kunci: Analytical Hierarchy Process (AHP), evaluasi kerusakan, estimasi biaya, suistanability.

\section{Abstract}

The sustainability of buildings was influence of life time that mean use of building according to the plan.It must be do periodic maintanance, so as able to maintance users comfort. The aim of this study was to index the damage of the building conditions, the priority scale for the repair and the cost estimation of the FKIP building 1 at the University of Jember. Method for getting the building condition ind ex conducted thrue field survey, by weighting of the building components and sub-components, count with of the analytical hierarchy process (AHP). TThe result of Condition Index Building 1 The FKIP University of Jember is $87.85 \%$. This means that the building is still very good. the demage is $12.15 \%$ need maintenance. The cost estimation for the maintanance depends on the damage volume of each component, so that there is a value of Rp. 48,652,000.00 with the highest priority scale for improving the wall component by $25.9 \%$.

Keywords: Analytical Hierarchy Process (AHP), damage evaluation, cost estimation, suistainability.

\section{PENDAHULUAN}

Bangunan gedung marupakan struktur buatan manusia yang terdiri dari komponen utama balok dan kolom. Fungsi dari bangunan gedung bermacam-macam, beberapa diantaranya antara lain sebagai tempat tinggal, tempat penyimpanan, tempat belajar menangajar, tempat bekerja, dan sebagainya.

Penggunaan bangunan gedung dalam jangka waktu yang cukup lama akan dapat menimbulkan kerusakan pada komponen-komponen gedung tersebut. Menurut Ismanto [1] tidak berfungsinya komponen bangunan yang diakibatkan karena penyusutan, berakhirnya umur bangunan, atau akibat ulah manusia, atau akibat perilaku alam (gempa bumi, penurunan tanah, banjir, dan lain-lain) atau akibat beban fungsi yang berlebihan, atau juga akibat pengaruh fisik/kimia/serangga dinamakan kerusakan bangunan. Pemeliharaan bangunan secara berkala perlu dilakukan untuk menjaga sustainability gedung sehingga dapat mencegah terjadinya kegagalan bangunan. Menurut Wijayanti [2] dalam memilih material bangunan, sebaiknya mengetahui masa layan material sehingga dalam membuat perencanaan dapat dipilih material dengan umur layan yang lama dengan tujuan efisiensi biaya pemeliharaannya. Seiring berjalannya waktu, umur layan material dapat mengurangi kualitas dan menurun performanya. Penurunan kualitas material dan bangunan bisa berpengaruh besar terutama dari segi keselamatan.

Gedung 1 Fakultas Keguruan dan Ilmu Pendidikan (FKIP) merupakan salah satu bangunan gedung yang telah berdiri cukup lama di kawasan Universitas Jember. Pemakaian gedung yang cukup lama ini dapat menimbulkan munculnya kerusakan-kerusakan pada tiap komponennya, sehingga perlu dilakukan identifikasi tingkat kerusakan dan 
juga volume kerusakan yang ada di Gedung 1 FKIP. Identifikasi tingkat kerusakan dan juga volume kerusakan ini diperperlukan agar dapat diketahui kondisi bangunan gedung secara keseluruhan dan juga volume kerusakan dari masing-masing komponennya sehingga dapat diketahui perbaikan kerusakan yang diperlukan dan biaya pemeliharaan pada Gedung 1 FKIP.

Tingkat kenyamanan pengguna dari Gedung 1 FKIP ini juga perlu untuk ditinjau, oleh karena itu perlu ditentukan skala prioritas penanganan pemeliharaan dari masingmasing komponenya. Salah satu metode yang digunakan dalam menentukan prioritas penanganan pemeliharaan atau bobot fungsi komponen bangunan dapat menggunakan metode AHP. Menurut Saaty [3] Anaytical Hierarchy Process (AHP) merupakan suatu proses pengambilan keputusan suatu masalah-masalah kompleks seperti permasalahan perencanaan, penentuan alternatif, penyusunan prioritas, pemilihan kebijaksanaan, alokasi sumber penentuan kebutuhan, peramalan kebutuhan perencanaan performance, optimasi, dan pemecahan konflik. Dengan menggunakan metode AHP ini, penentuan skala prioritas pemeliharan dapat ditentukan berdasarkan tingkat kenyamanan dari pengguna Gedung 1 FKIP Universitas Jember.

\section{METODE PENELITIAN}

Penelitian ini merupakan studi kasus tingkat kerusakan bangunan gedung di Gedung I Fakultas Keguruan dan Ilmu Pendidikan (FKIP) Universitas Jember. Penelitian ini bertujuan untuk menentukan tingkat kerusakan bangunan dan menentukan prioritas perbaikan bangunan serta mengestimasi biaya perbaikan bangunan di wilayah tersebut. Lokasi dan Waktu Penelitian Sumber data bangunan gedung diambil pada lokasi Gedung 1 Fakultas Keguruan dan Ilmu Pendidikan (FKIP) di area Universitas Jember Kecamatan Tegalboto Kabupaten Jember. Peta lokasi Gedung 1 FKIP berada diantara Lapangan Tenis dan Masjid Universitas Jember seperti terlihat pada Gambar 1 berikut.

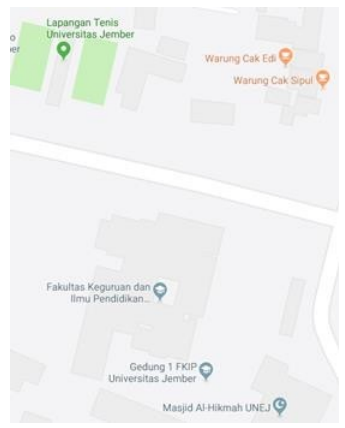

\section{Gambar 1. Lokasi Gedung 1 FKIP}

Waktu penelitian secara keseluruhan dilakukan selama kurang lebih lima bulan yaitu pada bulan Juli sampai dengan bulan November. Pelaksanaan survey lapangan dilakukan pada tiga minggu pertama waktu penelitian. Dua bulan selanjutnya digunakan untuk input data sampai dengan analisis data. Kemudian dua bulan setelahnya digunakan untuk penulisan hasil dari analisis data penelitian yang telah dilakukan.

\section{Tahapan Penelitian}

Tahapan pertama dalam penelitian ini adalah melakukan studi literatur. Studi literatur yang perlu dipelajari adalah studi mengenai metode penilaian kondisi gedung dan metode pengambilan keputusan. Hasil dari studi literature mengenai metode penilaian kerusakan gedung menggunakan kriteria yang ditetapkan oleh Direktorat Jendral Cipta Karya [4] mengenai kategori kerusakan pada bangunan gedung. Kategori ini dibagi menjadi tiga macam kerusakan, yaitu rusak ringan, rusak sedang, dan rusak berat.

Kategori kerusakan pada komponen struktur bangunan rusak ringan apabila kerusakan pada komponen struktur tidak mengurangi fungsi layan bangunan secara keseluruhan yaitu terjadi retak kecil dengan lebar celah sebesar 0,075 hingga $0,6 \mathrm{~cm}$. Kategori rusak sedang terjadi pada komponen struktur yang mengalami retak besar sehingga dapat mengurangi fungsi layan pada bangunan tersebut. Rusak berat merupakan kategori kerusakan pada komponen struktur yang mengalami kerusakan lebih besar dari 50\% pada elemen utama atau bisa dikatakan tidak layak huni.

Sama halnya dengan kategori kerusakan pada komponen struktur, komponen arsitektur atau non struktur memiliki tiga kategori kerusakan, yaitu rusak ringan, rusak sedang, dan rusak berat. Rusak ringan pada komponen arsitektur merupakan kerusakan yang tidak mengganggu fungsi bangunan dari segi arsitektur dan tidak menimbulkan bahaya sedikitpun pada penghuni seperti mengelupasnya cat pada dinding. Rusak sedang merupakan kerusakan yang dapat mengganggu fungsi bangunan dari segi arsitektur sehingga dapat menimbulkan rasa tidak nyaman pada penghuni, misalnya seperti pecahnya kaca jendela atau rusaknya daun pintu. Rusak berat merupakan kerusakan komponen yang sangat mengganggu fungsi dan estetika bangunan serta dapat menimbulkan rasa tidak nyaman dan menimbulkan bahaya pada penghuni.

Studi literatur mengenai metode pengambilan keputusan ditentukan menggunakan metode Anaytical Hierarchy Process (AHP). Metode ini digunakan untuk mendapatkan bobot dari masing-masing komponen gedung sehingga dapat ditentukan skala prioritas pemeliharaan bangunan gedung. Tahap awal dari metode ini perlu dilakukan penyusunan skema hierarki bangunan gedung. Hasil penyusunan skema hierarki bangunan dapat dilihat pada Gambar 2.

Hasil penyusunan skema hierarki bangunan tersebut dapat digunakan untuk menyusun kriteria dan sub kriteria yang akan digunakan untuk perhitungan bobot komponen dan juga penentuan kondisi bangunan. Hasil penyusunan kriteria dan sub kriteria adalah kriteria gedung memiliki sub kriteria struktur dan arsitektur, kriteria struktur memiliki sub kriteria balok dan kolom, kriteria arsitektur memiliki sub kriteria plafon, dinding, pintu, jendela dan lantai, dan kriteria seterusnya bisa dilihat dari skema hierarki bangunan tersebut. 


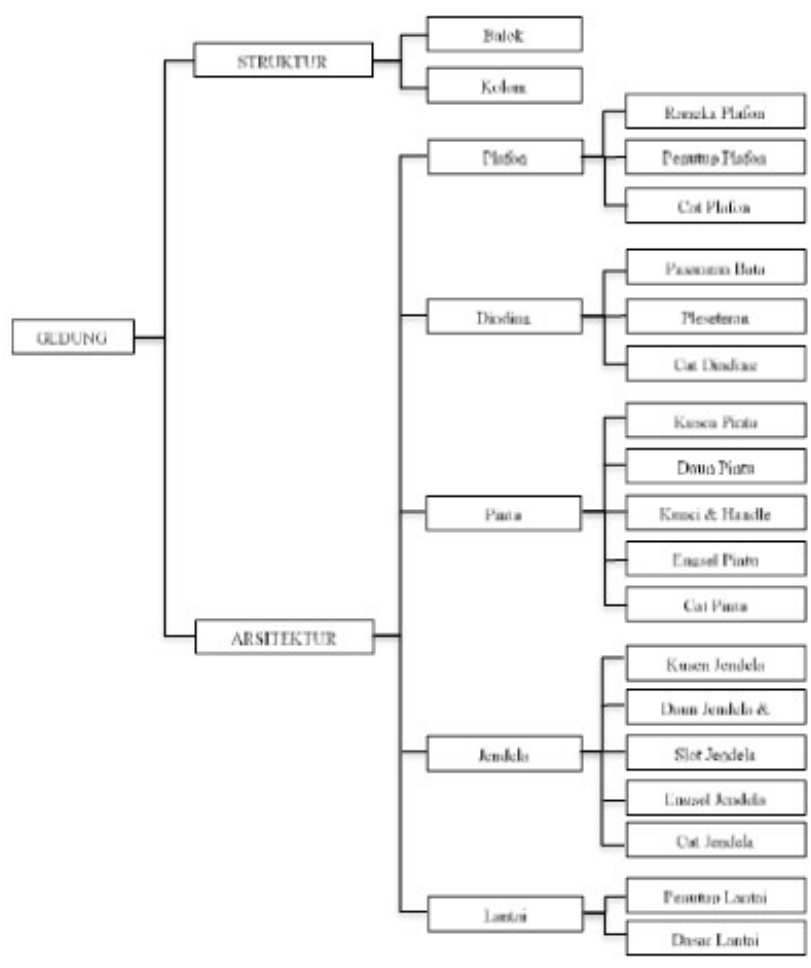

Gambar 2. Skema Hierarki Bangunan Gedung

Tahapan selanjutnya setelah penyusunan kriteria dan sub kriteria merupakan penyusunan form pengambilan data serta survey lapangan untuk mengambil data yang ada di lokasi penelitian. Data primer yang perlu diambil untuk keperluan analisis data antara lain data volume kerusakan dan volume total masing-masing komponen gedung dan data kuesioner mengenai tingkat kenyamanan pengguna gedung. Responden yang ditarget untuk pengisian kuesioner ini sebanyak 40 responden yang merupakan mahasiswa, staff, ataupun dosen pengajar di Jurusan Pendidikan IPS Fakultas Keguruan dan Ilmu Pendidikan (FKIP) sebagai penghuni dari Gedung 1 FKIP ini. Selain data primer, pengambilan data sekunder juga perlu dilakukan. Data sekunder yang didapatkan merupakan data harga satuan upah dan bahan Kabupaten Jember 2019 yang didapatkan dari Dinas PU Kabupaten Jember.

Tahapan berikutnya setelah pengambilan data adalah mengidentifikasi tingkat kerusakan dan rasio kerusakan komponen gedung, menghitung bobot dari masing-masing komponen gedung dan menghitung nilai indeks kondisi komponen gedung serta indeks kondisi bangunan. Penentuan tingkat kerusakan didapatkan dari hasil observasi di lokasi penelitian, sedangkan rasio kerusakan didapatkan dari perbandingan volume kerusakan dengan volume total dari komponen bangunan gedung tersebut. Perhitungan bobot dari masing-masing komponen gedung dapat dilihat pada uraian berikut.

a. Melakukan perkalian elemen-elemen dalam satu baris dan diakar pangkat $\mathrm{n}$

$w_{1}=\sqrt[n]{a_{11} \times a_{12} \times a_{13} \times \ldots \ldots a_{1 n}}$

b. Menghitung vektor prioritas atau eigen vector, hasil yang didapat berupa eigen vector sebagai bobot elemen.

$x_{1}=\frac{w_{i}}{\Sigma w_{i}}$. c. Menghitung nilai eigen maksimum ( $\lambda$ maks) dengan cara mengalikan matriks respirokal dengan bobot yang didapat, hasil dari penjumlahan operasi matriks adalah nilai eigen maksimum ( $\lambda$ maks)

$$
\lambda_{\text {maks }}=\sum a_{i j} \cdot x_{i}
$$

dengan:

$\lambda$ maks $=$ eigen maksimum

$\sum a_{i j}=$ nilai matriks perbandingan berpasangan

$\mathrm{x}_{\mathrm{i}} \quad=$ vector eigen (bobot)

d. Perhitungan indeks konsistensi, perhitungan ini untuk mengetahui konsistensi jawaban yang akan berpengaruh kepada kesahihan hasil.

$$
C I=\frac{\lambda_{\text {maks }}-1}{n-1}
$$

e. Perhitungan konsistensi rasio, matriks perbandingan dapat diterima apabila nilai rasio konsistensi $<0.1$

$$
C R=\frac{C I}{R I}
$$

Nilai Random Indeks (RI) tergantung ukuran matriks sebagaimana terlihat pada Tabel 1.

Tabel 1. Hubungan antara ukuran matriks dan nilai RI

\begin{tabular}{|c|c|c|c|c|c|c|c|c|c|c|c|c|c|c|c|}
\hline Matriks & 1 & 2 & 3 & 4 & 5 & 6 & 7 & 8 & 9 & 10 & 11 & 12 & 13 & 14 & 15 \\
\hline RI & 0 & 0 & 0.5 & 0.9 & 1.12 & 1.24 & 1.32 & 1.41 & 1.45 & 1.49 & 1.51 & 1.48 & 1.56 & 1.57 & 1.59 \\
\hline
\end{tabular}

\begin{tabular}{|c|c|}
\hline 1 & $\begin{array}{l}\text { Elemen yang sama Kedua elemen } \\
\text { pentingnya dibanding menyumbang } \\
\text { dengan elemen yang sama besar pada } \\
\text { lain (Equal Importance) } \\
\text { sifat tersebut }\end{array}$ \\
\hline 3 & $\begin{array}{l}\text { Elemen yang satu Pengalaman } \\
\text { sedikit lebih penting menyatakan } \\
\text { daripada elemen yang sedikit berpihak } \\
\text { lain (Moderate more pada satu elemen } \\
\text { importance) }\end{array}$ \\
\hline 5 & $\begin{array}{ll}\text { Elemen yang satu jelas } & \text { Pengalaman } \\
\text { lebih penting dari pada menunjukan } \\
\text { elemen yang lain } & \text { secara kuat } \\
\text { (Essential, Strong more } & \text { memihak pada } \\
\text { importance) } & \text { satu elemen. }\end{array}$ \\
\hline 7 & $\begin{array}{lrll}\text { Elemen } & \text { yang } & \text { satu } & \text { Pengalaman } \\
\text { sangat jelas lebih } & \text { menunjukan } \\
\text { penting } & \text { daripada } & \text { secara kuat } \\
\text { elemen yang lain } & \text { disukai dan } \\
\text { (Demonstrated elemen) } & \text { dominan dalam } \\
& & & \text { praktek }\end{array}$ \\
\hline 9 & 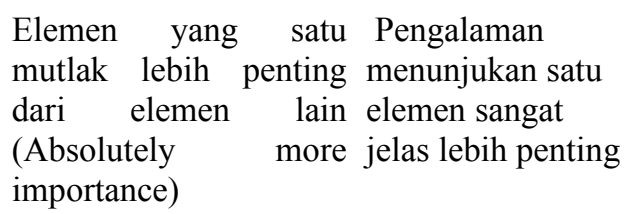 \\
\hline
\end{tabular}

Tabel 2. Skala penilaian perbandingan pasangan

\begin{tabular}{ccc}
\hline Intensitas & Definisi & Penjelasan \\
Kepentingan & &
\end{tabular}


Pada penetapan bobot komponen / elemen menggunakan model AHP ini, syarat penyusunan matriks perbandingan dapat diterima apabila nilai $\mathrm{CR} \leq 0,1$ Perhitungan nilai bobot dari masing-masing komponen ini dilakukan dengan menggunakan alat bantu program Expert Choice v11 sehingga analisa data kuesioner dari 40 responden dapat selesai lebih cepat. Penetapan skala kuantitatif 1 (satu) sampai dengan 9 (Sembilan) untuk menilai perbandingan tingkat kepentingan suatu elemen terhadap yang lain dapat dilihat pada Tabel 2 .

Tahapan selanjutnya setelah didapatkan nilai bobot dan identifikasi kerusakan ialah perhitungan Indeks Kondisi Bangunan (IKB). Terdapat dua tahap dalam perhitungan ini, tahapan pertama adalah perhitungan Indeks Kondisi Sub Elemen (IKSE) dan Indeks Kondisi Elemen (IKE). Perhitungan Indeks Kondisi Sub Elemen adalah sebagai berikut.

$I K S E=100-\sum_{i=1}^{p} \sum_{j=1}^{m} a(T j \times S j \times D i j) \times F(t, d)$

dengan:

$$
\begin{aligned}
& \text { a } \quad=\text { Nilai pengurang } \\
& \mathrm{p}=\text { Jumlah jenis kerusakan untuk kelompok sub } \\
& \text { eleman yang ditinjau } \\
& \mathrm{m}=\text { Jumlah tingkat kerusakan untuk jenis kerusaan } \\
& \text { ke-1 } \\
& \mathrm{F}(\mathrm{t}, \mathrm{d})=\text { Faktor koreksi untuk kerusakan berganda }
\end{aligned}
$$

Besarnya nilai pengurang besarnya antara 0 (nol) hingga100 (seratus), tergantung pada jenis kerusakan $(\mathrm{Tj})$, tingkat kerusakan (Sj), dan kuantitas kerusakan (Dij). Faktor koreksi tergantung pada tingkat bahaya tiap jenis kerusakan, dengan jumlah faktor koreksi untuk semua jenis koreksi adalah satu, seperti pada Tabel 3.

Tabel 3. Faktor koreksi untuk kombinasi kerusakan

\begin{tabular}{cccc}
\hline No & $\begin{array}{c}\text { Jumlah Kombiasi } \\
\text { Kerusakan }\end{array}$ & $\begin{array}{c}\text { Prioritas } \\
\text { Bahaya } \\
\text { Kerusakan }\end{array}$ & $\begin{array}{c}\text { Faktor Koreksi } \\
\mathrm{F}(\mathrm{t}, \mathrm{d})\end{array}$ \\
\hline 1 & 2 & I & $0,8-0,7-0,6$ \\
\cline { 2 - 4 } & 3 & II & $0,2-0,3-0,4$ \\
\hline 2 & & I & $0,5-0,6$ \\
\cline { 2 - 4 } & & II & $0,3-0,4$ \\
\cline { 2 - 4 } & & III & $0,1-0,2$ \\
\hline
\end{tabular}

Pehitungan Indeks Kondisi Elemen (IKE) dan Indeks Kondisi Bangunan (IKB) menggunakan rumus perhitungan Indeks Kondisi Gabungan (Composite Conditions Index) sebagai berikut.

$$
C C I=\sum_{i=1}^{n} W i \times C i
$$

dimana:

$$
\begin{array}{ll}
\mathrm{CCI} & =\text { Indeks Kondisi Gabungan } \\
\mathrm{W} & =\text { bobot komponen } \\
\mathrm{C} & =\text { nilai kondisi bangunan } \\
\mathrm{i}=1 & =\text { kompone ke- } 1 \\
\mathrm{n} & =\text { banyaknya komponen }
\end{array}
$$

\begin{tabular}{|c|c|c|c|}
\hline Zone & $\begin{array}{l}\text { Indeks } \\
\text { Kondisi }\end{array}$ & Uraian Kondisi & $\begin{array}{c}\text { Tindakan } \\
\text { Penanganan }\end{array}$ \\
\hline \multirow[t]{2}{*}{1} & $85-100$ & $\begin{array}{l}\text { Baik sekali: Tidak } \\
\text { terlihat kerusakan, } \\
\text { beberapa kekurangan } \\
\text { mungkin terlihat. }\end{array}$ & \multirow[t]{2}{*}{$\begin{array}{l}\text { Tindakan segera } \\
\text { masih belum } \\
\text { diperlukan. }\end{array}$} \\
\hline & $70-84$ & $\begin{array}{l}\text { Baik: Hanya } \\
\text { terjadi deteriorasi } \\
\text { atau kerusakan } \\
\text { kecil. }\end{array}$ & \\
\hline \multirow[t]{2}{*}{2} & $55-69$ & $\begin{array}{l}\text { Sedang: Mulai } \\
\text { terjadi deteriorasi } \\
\text { atau kerusakan } \\
\text { namun tidak } \\
\text { mempengaruhi } \\
\text { fungsi struktur } \\
\text { bangunan secara } \\
\text { keseluruhan. }\end{array}$ & \multirow[t]{2}{*}{$\begin{array}{l}\text { Perlu dibuat } \\
\text { analisis } \\
\text { ekonomi } \\
\text { Alternatif } \\
\text { perbaikan untuk } \\
\text { menetapkan } \\
\text { tindakan yang } \\
\text { sesuai/tepat }\end{array}$} \\
\hline & $40-54$ & $\begin{array}{l}\text { Cukup: Terjadi } \\
\text { deteriorasi atau } \\
\text { kerusakan tetapi } \\
\text { bangunan masih } \\
\text { cukup berfungsi. }\end{array}$ & \\
\hline \multirow[t]{3}{*}{3} & $25-39$ & $\begin{array}{l}\text { Buruk: Terjadi } \\
\text { kerusakan yang } \\
\text { cukup kritis sehingga } \\
\text { fungsi bangunan } \\
\text { terganggu }\end{array}$ & \multirow{3}{*}{$\begin{array}{l}\text { Evaluasi secara } \\
\text { detaildiperlukan } \\
\text { untuk } \\
\text { menentukan } \\
\text { tindakan repair, } \\
\text { rehabilitasi dan } \\
\text { rekonstruksi, } \\
\text { selain } \\
\text { diperlukan } \\
\text { evaluasi untuk } \\
\text { keamanan. }\end{array}$} \\
\hline & $10-24$ & $\begin{array}{l}\text { Sangat buruk: } \\
\text { Kerusakan parah dan } \\
\text { bangunan hampir } \\
\text { tidak berfungsi. }\end{array}$ & \\
\hline & $0-9$ & $\begin{array}{l}\text { Runtuh: Pada } \\
\text { komponen utama } \\
\text { bangunan terjadi } \\
\text { keruntuhan. }\end{array}$ & \\
\hline
\end{tabular}

Nilai indeks kondisi mempunyai skala antara 0 (nol) hingga 100 (seratus), yang menggambarkan tingkat kondisi bangunan. Indeks kondisi bernilai 0 berarti bangunan sudah tidak berfungsi dan 100 untuk bangunan yang masih dalam kondisi baik sekali. Nilai Indeks kondisi dapat digunakan sebagai dasar dalam penanganan bangunan dengan berpedoman pada Tabel 4 berikut.

Tabel 4. Skala Indeks Kondisi

Tahapan terakhir pada penelitian ini adalah menghitung rencana anggaran biaya perbaikan pada komponen komponen gedung yang mengalami kerusakan. Tahapan perhitungan rencana anggaran biaya dapat dilihat pada Gambar 3 .

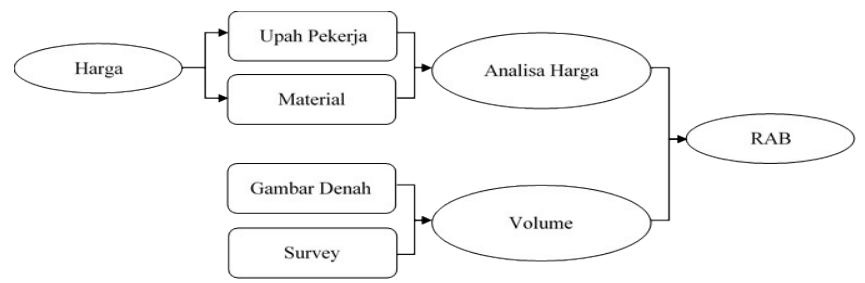

Gambar 3. Skema Penyusunan Rencana Anggaran Biaya

Harga satuan dari upah pekerja dan bahan didapatkan dari data sekunder AHS Kabupaten Jember 2019. Perhitungan volume pekerjaan didapatkan dari hasil total volume kerusakan pada masing-masing komponen gedung. Garis besar tahapan-tahapan yang perlu dilakukan untuk melakukan penelitian ini dapat dilihat pada Gambar 4. 


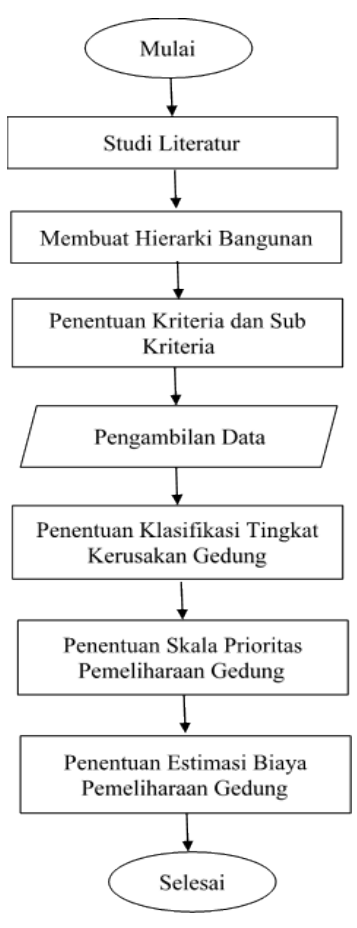

Gambar 4. Diagram Alur Penelitian

\section{HASIL DAN PEMBAHASAN}

\section{Analisa Kerusakan}

Hasil survey lapangan di lokasi penelitian yaitu Gedung 1 FKIP Universitas Jember ditemukan cukup banyak kerusakan pada komponen-komponen gedung tersebut. Beberapa contoh kerusakan yang cukup banyak ditemukan adalah lubang bekas paku pada dinding dan cat dinding yang terkelupas, penutup plafon yang berlubang dan hampir terlepas dari rangkanya, penutup lantai yang mengalami keretakan dan berlubang, serta beberapa kerusakankerusakan lainnya. Hasil lengkap evaluasi kerusakan komponen gedung dapat dilihat pada Tabel 5 berikut.

Tabel 5. Evaluasi Kerusakan Gedung 1 FKIP

\begin{tabular}{|c|c|c|c|c|c|c|c|}
\hline \multirow[b]{2}{*}{ No } & \multirow[b]{2}{*}{$\begin{array}{l}\text { Komponen Bangunan } \\
\text { Gedung }\end{array}$} & \multicolumn{3}{|c|}{ Volume } & \multicolumn{3}{|c|}{ Kerusakan } \\
\hline & & $\begin{array}{l}\text { Volume } \\
\text { Kerusakan }\end{array}$ & Volume Total & $\begin{array}{c}\text { Rasio } \\
\text { Kerusakan } \\
(\%)\end{array}$ & Ringan & SedangBerat & Baik \\
\hline 1 & Kolom & $0,000 \mathrm{~m}^{3}$ & $11,0 \mathrm{~m}^{3}$ & 0,000 & & & $\sqrt{ }$ \\
\hline 2 & Balok & $0,000 \mathrm{~m}^{3}$ & $14,8 \mathrm{~m}^{3}$ & 0,000 & & & $\sqrt{ }$ \\
\hline 3 & Rangka Plafon & $0,000 \mathrm{~m}^{3}$ & $6,0 \mathrm{~m}^{3}$ & 0,000 & & & $\sqrt{1}$ \\
\hline 4 & $\begin{array}{l}\text { Penutup Plafon } \\
\end{array}$ & $12,000 \mathrm{~m}^{2}$ & $1945,5 \mathrm{~m}^{2}$ & 0,617 & & $\sqrt{ }$ & \\
\hline 5 & Cat Plafon & $30,000 \mathrm{~m}^{2}$ & $1945,5 \mathrm{~m}^{2}$ & 1,542 & $\sqrt{ }$ & & \\
\hline 6 & $\begin{array}{l}\text { Pasangan Bata } \\
\text { nan }\end{array}$ & $0,000 \mathrm{~m}^{3}$ & $275,2 \mathrm{~m}^{3}$ & 0,000 & & & $\sqrt{1}$ \\
\hline$\overline{7}$ & Plesteran & $427,109 \mathrm{~m}^{2}$ & $3578,0 \mathrm{~m}^{2}$ & 11,937 & & $\sqrt{ }$ & \\
\hline 8 & Cat Dinding & $482,649 \mathrm{~m}^{2}$ & $3578,0 \mathrm{~m}^{2}$ & 13,489 & $\mathrm{v}$ & & \\
\hline 9 & Kusen Pintu & $0,000 \mathrm{~m}^{3}$ & $3,7 \mathrm{~m}^{3}$ & 0,000 & & & $\sqrt{ }$ \\
\hline 10 & Daun Pintu & $0,542 \mathrm{~m}^{2}$ & $104,5 \mathrm{~m}^{2}$ & 0,519 & $\sqrt{ }$ & & \\
\hline 11 & Kunci \& Handel Pintu & 1,000 unit & 54 unit & 1,852 & & $\sqrt{ }$ & \\
\hline 12 & Engsel Pintu & 0,000 unit & 108 unit & 0,000 & & & $\sqrt{1}$ \\
\hline 13 & Cat Pintu & $0,000 \mathrm{~m}^{2}$ & $209,0 \mathrm{~m}^{2}$ & 0,000 & & & $\sqrt{1}$ \\
\hline 14 & $\begin{array}{l}\text { Kusen Jendela } \\
\end{array}$ & $0,348 \mathrm{~m}^{3}$ & $5,3 \mathrm{~m}^{3}$ & 6,565 & & $\mathrm{~V}$ & \\
\hline 15 & Daun Jendela \& Kaca & $1,840 \mathrm{~m}^{2}$ & $310,3 \mathrm{~m}^{2}$ & 0,593 & & $\sqrt{ }$ & \\
\hline 16 & Slot Jendela & 0,000 unit & 93 unit & 0,000 & & & $\sqrt{ }$ \\
\hline 17 & Engsel Jendela & 0,000 unit & 186 unit & 0,000 & & & $\sqrt{1}$ \\
\hline 18 & Cat Jendela & $0,000 \mathrm{~m}^{2}$ & $310,3 \mathrm{~m}^{2}$ & 0,000 & & & $\sqrt{1}$ \\
\hline$\overline{19}$ & Penutup lantai & $3,830 \mathrm{~m}^{2}$ & $1945,5 \mathrm{~m}^{2}$ & 0,197 & & $\sqrt{ }$ & \\
\hline$\overline{20}$ & Dasar lantai & $0,000 \mathrm{~m}^{3}$ & $972,8 \mathrm{~m}^{3}$ & 0,000 & & & $\sqrt{ }$ \\
\hline
\end{tabular}

\section{Pembobotan Komponen Bangunan Gedung}

Hasil pembobotan komponen bangunan gedung didapat dari hasil analisis menggunakan metode AHP dengan bantuan program Expert Choice v11. Total responden yang didapat dalam penelitian ini sebanyak 40 responden yang terdiri dari mahasiswa, dan staff Jurusan Pendidikan IPS FKIP. Hasil pembobotan ini didapatkan berdasarkan jawaban respondenresponden tersebut mengenai tingkat kenyamanan pengguna terhadap kondisi komponenkomponen gedung di ruangan yang biasa responden tempati. Hasil dari analisis perhitungan bobot dari masingmasing komponen gedung ini bisa dilihat di Tabel 6 berikut.

Tabel 6. Bobot Komponen Gedung 1 FKIP

\begin{tabular}{|c|c|c|c|c|c|}
\hline \multirow{2}{*}{ Struktur } & \multirow{2}{*}{0,471} & \multirow{2}{*}{\multicolumn{2}{|c|}{$\begin{array}{c}\text { Balok } \\
\text { Kolom } \\
\end{array}$}} & \multicolumn{2}{|l|}{0,501} \\
\hline & & & & 0,499 & \\
\hline \multirow{18}{*}{ Arsitektur } & \multirow{18}{*}{0,529} & \multirow{3}{*}{ Plafon } & \multirow{3}{*}{0,201} & Rangka plafon & 0,325 \\
\hline & & & & Penutup plafon & 0,363 \\
\hline & & & & Cat plafon & 0,312 \\
\hline & & \multirow{3}{*}{ Dinding } & \multirow{3}{*}{0,259} & Pasangan bata & 0,381 \\
\hline & & & & Plesteran dinding & 0,288 \\
\hline & & & & Cat dinding & 0,331 \\
\hline & & \multirow{5}{*}{ Pintu } & \multirow{5}{*}{0,195} & Kusen pintu & 0,232 \\
\hline & & & & Daun pintu & 0,197 \\
\hline & & & & Kunci \& handle & 0,224 \\
\hline & & & & Engsel pintu & 0,167 \\
\hline & & & & Cat pintu & 0,179 \\
\hline & & \multirow{5}{*}{ Jendela } & \multirow{5}{*}{0,184} & Kusen jendela & 0,232 \\
\hline & & & & Daun jendela \& kaca & 0,205 \\
\hline & & & & Slot jendela & 0,192 \\
\hline & & & & Engsel jendela & 0,189 \\
\hline & & & & Cat jendela & 0,182 \\
\hline & & \multirow[t]{2}{*}{ Lantai } & \multirow[t]{2}{*}{0,16} & Penutup lantai & 0,533 \\
\hline & & & & Dasar lantai & 0,467 \\
\hline
\end{tabular}

Prioritas tertinggi untuk pemeliharaan bangunan Gedung 1 FKIP Universitas Jember menurut Tabel 6.1 adalah komponen arsitektur dengan nilai bobot sebesar $52,9 \%$. Sub komponen dari komponen arsitektur yang mendapat prioritas tertinggi adalah sub komponen dinding dengan bobot sebesar 25,9\% dan prioritas terendah adalah sub komponen lantai dengan bobot sebesar 16\%. Indeks Kondisi Bangunan Gedung Hasil yang didapat dari perhitungan Indeks Kondisi Bangunan (IKB) menunjukkan kondisi bangunan gedung yang sedang ditinjau. Seperti halnya yang dapat dilihat di Tabel 4, skor yang didapatkan dari hasil survey lapangan dapat menunjukkan kondisi bangunan secara keseluruhan. Sebelum didapatkan hasil skor Indeks Kondisi Bangunan (IKB) perlu dihitung terlebih dahulu Indeks Kondisi Sub Elemen (IKSE) dan Indeks Kondisi Elemen (IKE). Contoh hasil perhitungan IKSE dan IKE pada komponen dinding dapat dilihat pada Tabel 7 dan Tabel 8.

Tabel 7. Indeks Kondisi Sub Elemen Dinding

\begin{tabular}{|c|c|c|c|c|c|c|}
\hline \multirow[b]{2}{*}{ Elemen } & \multirow[b]{2}{*}{ Sub Elemen } & \multicolumn{3}{|c|}{ Rasio } & & \multirow[b]{2}{*}{$\begin{array}{l}\text { Indeks } \\
\text { Kondisi } \\
\text { Sub } \\
\text { Elemen } \\
\text { (IKSE) }\end{array}$} \\
\hline & & Jenis Kerusakan & $\begin{array}{c}\text { Kerusakan } \\
(\%)\end{array}$ & FK & NP & \\
\hline \multirow{6}{*}{ Dinding } & \multirow{4}{*}{$\frac{\text { Pas Bata }}{\text { Plesteran }}$} & berlubang & 0 & 0 & 0 & \multirow[t]{2}{*}{100} \\
\hline & & retak & 0 & 0 & 0 & \\
\hline & & berlubang & 11,937 & 0,6 & 40 & 60 \\
\hline & & retak & 11,937 & 0,4 & 40 & \\
\hline & \multirow[t]{2}{*}{ Cat Dinding } & berlumut & 13,489 & 0,6 & 45 & \multirow{2}{*}{55} \\
\hline & & mengelupas & 13,489 & 0,4 & 45 & \\
\hline
\end{tabular}

Tabel 8. Indeks Elemen Dinding

\begin{tabular}{|l|l|l|l|l|}
\hline \multirow{2}{*}{ Elemen } & Sub Elemen & $\begin{array}{l}\text { Indeks Kondisi Sub } \\
\text { Elemen (IKSE) }\end{array}$ & $\begin{array}{l}\text { Bobot } \\
\text { Elemen }\end{array}$ & $\begin{array}{l}\text { Indeks Kondisi } \\
\text { Elemen (IKE) }\end{array}$ \\
\hline \multirow{3}{*}{ Dinding } & Pas Bata & 100 & 0,381 & \multirow{2}{*}{73,59} \\
\cline { 2 - 4 } & Plesteran & 60 & 0,288 & \\
\cline { 2 - 4 } & Cat Dinding & 55 & 0,331 & \\
\hline
\end{tabular}

Perhitungan untuk komponen-komponen lainnya dilakukan sama seperti contoh perhitungan diatas sehingga 
didapatkan nilai Indeks Kondisi Elemen untuk komponen Struktur dan Arsitektur masing-masing sebesar 100\% dan $77,03 \%$. Perhitungan untuk Indeks Kondisi Bangunan (IKB) dapat dilihat pada Tabel 9.

Tabel 9. Indeks Kondisi Bangunan Gedung 1 FKIP

\begin{tabular}{clccc}
\hline Elemen & Sub Elemen & $\begin{array}{c}\text { Indeks Kondisi } \\
\text { Sub Elemen } \\
\text { (IKSE) }\end{array}$ & Bobot Elemet & $\begin{array}{c}\text { Indeks Kondisi } \\
\text { Elemen (IKE) }\end{array}$ \\
\hline Gedung & Struktur & 100,00 & 0,471 & \multirow{2}{*}{87,85} \\
\cline { 2 - 4 } & Arsitektur & 77,03 & 0,529 & \\
\hline
\end{tabular}

Hasil dari Tabel 9 apabila ditinjau dari Tabel 4 maka dapat disimpulkan bahwa kondisi bangunan Gedung 1 FKIP berada di Zona 1. Indeks tersebut menunjukkan bahwa kondisi Gedung 1 FKIP Universitas Jember secara keseluruhan sangat baik, hanya saja terlihat beberapa kekurangan pada komponen-komponennya.

\section{Rencana Anggaran Biaya Perbaikan}

Rencana anggaran biaya (RAB) perbaikan bangunan Gedung 1 FKIP Universitas Jember didapatkan berdasarkan volume kerusakan masing-masing komponen bangunan gedung yang didapat dari survey lapangan. Harga satuan upah dan bahan yang dipakai merupakan harga satuam di Kabupaten Jember tahun 2019. Sebelum mulai menghitung rencana anggaran biaya (RAB) perbaikan, perlu dihitung terlebih dahulu analisa harga satuan pekerjaan tiap masingmasing komponen. Contoh perhitungan analisa harga satuan pekerjaan perbaikan pada komponen dinding dapat dilihat pada Tabel 10 .

Tabel 10. Analisa Harga Satuan Pekerjaan Dinding

\begin{tabular}{|c|c|c|c|c|c|}
\hline No & Uraian Pekerjaan & Sat. & Koef. & $\begin{array}{c}\text { Harga Satuan } \\
\text { (Rp) }\end{array}$ & Jumlah (Rp) \\
\hline I & PEKERJAAN DINDING & & & & \\
\hline \multirow[t]{4}{*}{1} & Pembongkaran Plesteran & $\mathrm{m}^{2}$ & 1 & & \\
\hline & Pekerja & $\mathrm{OH}$ & 0,05 & $78.900,00$ & $3.945,00$ \\
\hline & Mandor & $\mathrm{OH}$ & 0,003 & $119.400,00$ & 298,50 \\
\hline & Jumlah & & & & $4.243,50$ \\
\hline \multirow[t]{8}{*}{2} & Plesteran & $\mathrm{m}^{2}$ & 1 & & \\
\hline & Semen PC 50kg & zak & 0,156 & $80.000,00$ & $12.480,00$ \\
\hline & Pasir pasang & $\mathrm{m}^{3}$ & 0,023 & $211.700,00$ & $4.869,10$ \\
\hline & Pekerja & $\mathrm{OH}$ & 0,3 & $78.900,00$ & $23.670,00$ \\
\hline & Tukang Batu & $\mathrm{OH}$ & 0,15 & $101.300,00$ & $15.195,00$ \\
\hline & Kepala Tukang Batu & $\mathrm{OH}$ & 0,015 & $112.600,00$ & $1.689,00$ \\
\hline & $\overline{\text { Mandor }}$ & $\mathrm{OH}$ & 0,015 & $119.400,00$ & $1.791,00$ \\
\hline & Jumlah & & & & $59.694,10$ \\
\hline \multirow[t]{8}{*}{3} & Pengecatan Dinding & $\mathrm{m}^{2}$ & 1 & & \\
\hline & Cat Tembok & $\mathrm{kg}$ & 0,36 & $56.000,00$ & $20.160,00$ \\
\hline & Kuas & $\mathrm{klg}$ & 0,01 & $4.700,00$ & 47,00 \\
\hline & $\overline{\text { Pekerja }}$ & $\mathrm{OH}$ & 0,028 & $78.900,00$ & $2.209,20$ \\
\hline & Tukang Cat & $\mathrm{OH}$ & 0,042 & $101.300,00$ & $4.254,60$ \\
\hline & Kepala Tukang Cat & $\mathrm{OH}$ & 0,004 & $112.600,00$ & 450,40 \\
\hline & Mandor & $\mathrm{OH}$ & 0,003 & $119.400,00$ & 358,20 \\
\hline & Jumlah & & & & $27.479,40$ \\
\hline
\end{tabular}

Pekerjaan perbaikan pada dinding ini meliputi pekerjaan pembongkaran plesteran pada bagian dinding yang akan di cat ulang atau mengalami kerusakan. Pekerjaan berikutnya adalah melakukan pekerjaan plesteran pada bagian dinding yang telah dibongkar sebelumnya. Pekerjaan terakhir yang dilakukan adalah melakukan cat ulang pada bagian dinding yang telah diperbaiki.

Perhitungan analisa harga satuan pekerjaan perbaikan dilakukan pada tiap komponen-komponen yang mengalami kerusakan dengan cara yang hampir sama dengan pekerjaan dinding di Tabel 10. Rincian perhitungan Rencana Anggara Biaya Perbaikan dapat dilihat pada Tabel 11.

Tabel 11. RAB Perbaikan Gedung 1 FKIP

\begin{tabular}{|c|c|c|c|c|}
\hline No & Pekerjaan & Volume Pekerjaan & AHSP (Rp) & RAB (Rp) \\
\hline I & PEKERJAAN DINDING & & & \\
\hline 1 & Pembongkaran plesteran & 427,109 & $4.243,50$ & $1.812 .436,45$ \\
\hline 2 & Plesteran & 427,109 & $59.694,10$ & $25.495 .879,00$ \\
\hline 3 & Pengecatan dinding & 482,649 & $27.479,40$ & $13.262 .901,08$ \\
\hline II & \multicolumn{4}{|c|}{ PEKERJAAN PLAFON } \\
\hline 1 & Pembongkaran plafon & 12,000 & $5.544,00$ & $66.528,00$ \\
\hline 2 & Pemasangan plafon & 12,000 & $162.950,50$ & $\overline{1.955 .406,00}$ \\
\hline 3 & Pengecatan plafon & 30,000 & $27.479,40$ & $824.382,00$ \\
\hline III & \multicolumn{4}{|c|}{ 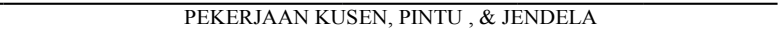 } \\
\hline 1 & Pembongkaran kusen & 0,348 & $112.560,00$ & $39.181,01$ \\
\hline 2 & Pembongkaran daun pintu & 0,542 & $1.697,40$ & $\overline{919,99}$ \\
\hline 3 & Pembongkaran kaca jendela & 1,840 & $2.725,20$ & $5.014,37$ \\
\hline 4 & Pemasangan kusen & 0,348 & $10.264 .340,00$ & $3.572 .914,11$ \\
\hline 5 & Pemasangan daun pintu & 0,542 & $672.358,00$ & $\overline{364.418,04}$ \\
\hline 6 & Pemasangan kunci tanam biasa & 2 unit & $126.762,00$ & $\overline{253.524,00}$ \\
\hline 7 & Pemasangan kaca jendela & 1,840 & $206.657,70$ & $380.250,17$ \\
\hline 8 & $\begin{array}{l}\text { Pengecatan kusen, pintu, \& frame } \\
\text { jendela }\end{array}$ & 0,348 & $15.776,20$ & $5.491,54$ \\
\hline IV & \multicolumn{4}{|c|}{ PEKERJAAN LANTAI } \\
\hline 1 & Pembongkaran lantai & 3,830 & $9.084,00$ & $34.791,72$ \\
\hline 1 & Pemasangan lantai keramik $20 \times 20 \mathrm{~cm}$ & 2,120 & $143.374,70$ & $303.954,36$ \\
\hline 2 & Pemasangan lantai keramik $30 \times 30 \mathrm{~cm}$ & 1,710 & $160.116,10$ & $273.798,53$ \\
\hline & Jumlah & & & $48.651 .790,37$ \\
\hline
\end{tabular}

Dari tabel 11 tersebut maka dapat diimpulkan total biaya yang dibutuhkan untuk perbaikan bangunan Gedung 1 FKIP Universitas Jember sebesar Rp. 48.651.790,37 atau bisa dibulatkan menjadi sebesar Rp. 48.652.000,00.

\section{KESIMPULAN}

Berdasarkan dari hasil observasi lapangan dan perhitungan Indeks Kondisi Bangunan (IKB) di Gedung 1 FKIP Universitas Jember, bangunan ini masih layak digunakan untuk melakukan kegiatan belajar mengajar serta kegiatan administrasi. Meskipun gedung ini berumur cukup tua, pemeliharaan berkala yang dilakukan pada gedung ini cukup sering dilakukan. Pemeliharaan berkala ini membuat kondisi gedung masih terlihat bagus dan kokoh sehingga tidak terlalu banyak kerusakan yang ditemukan pada gedung ini.

Observasi yang dilakukan pada komponen struktur tidak dilakukan secara menyeluruh terhadap komponen struktur atap dan struktur bawah, sehingga nilai Indeks Kondisi Bangunan bisa berubah apabila dilakukan observasi lebih lanjut pada dua komponen ini. Selain itu, observasi dilakukan tanpa menggunakan alat bantu, sehingga kemungkinan tingkat dan volume kerusakan pada masingmasing komponen dapat berubah apabila dilakukan observasi lebih lanjut.

\section{UCAPAN TERIMA KASIH}

Penulis mengucapkan terima kasih kepada Ibu Dr.Anik Ratnaningsih, S.T.,M.T. dan Bapak Dwi Nurtanto, S.T.,M.T. yang telah membimbing penulis selama pengerjaan penelitian ini. Selain itu Penulis juga mengucapkan terima kasih kepada Bapak Dr. Sumardi, M.Hum beserta staff yang telah membantu proses pengambilan data secara administratif. 


\section{DAFTAR PUSTAKA}

[1] Ismanto. 2017. "Penentuan Prioritas Kegiatan Perawatan Bangunan Gedung Sekolah Negeri Di Kota Blitar".Malang: Universitas Brawijaya.

[2] Wijayanti, Atu Riska. (2015). "Skala Prioritas Pemeliharaan Gedung Kantor Balai Pelatihan Konstruksi Wilayah V Jayapura". Surakarta: Universitas Sebelas Maret Surakarta.

[3] Saaty, T.L..1986. "Proses Hirarki Analitik untuk Pengambilan Keputusan dalam Situasi yang Kompleks. Jakarta:PT Pustaka Binman Pressindo.

[4] Departemen Pekerjaan Umum, Direktorat Jenderal Cipta Karya. 2008. "Pedoman Pemeliharaan dan Perawatan Bangunan Gedung". Jakarta: Departemen Pekerjaan Umum. 